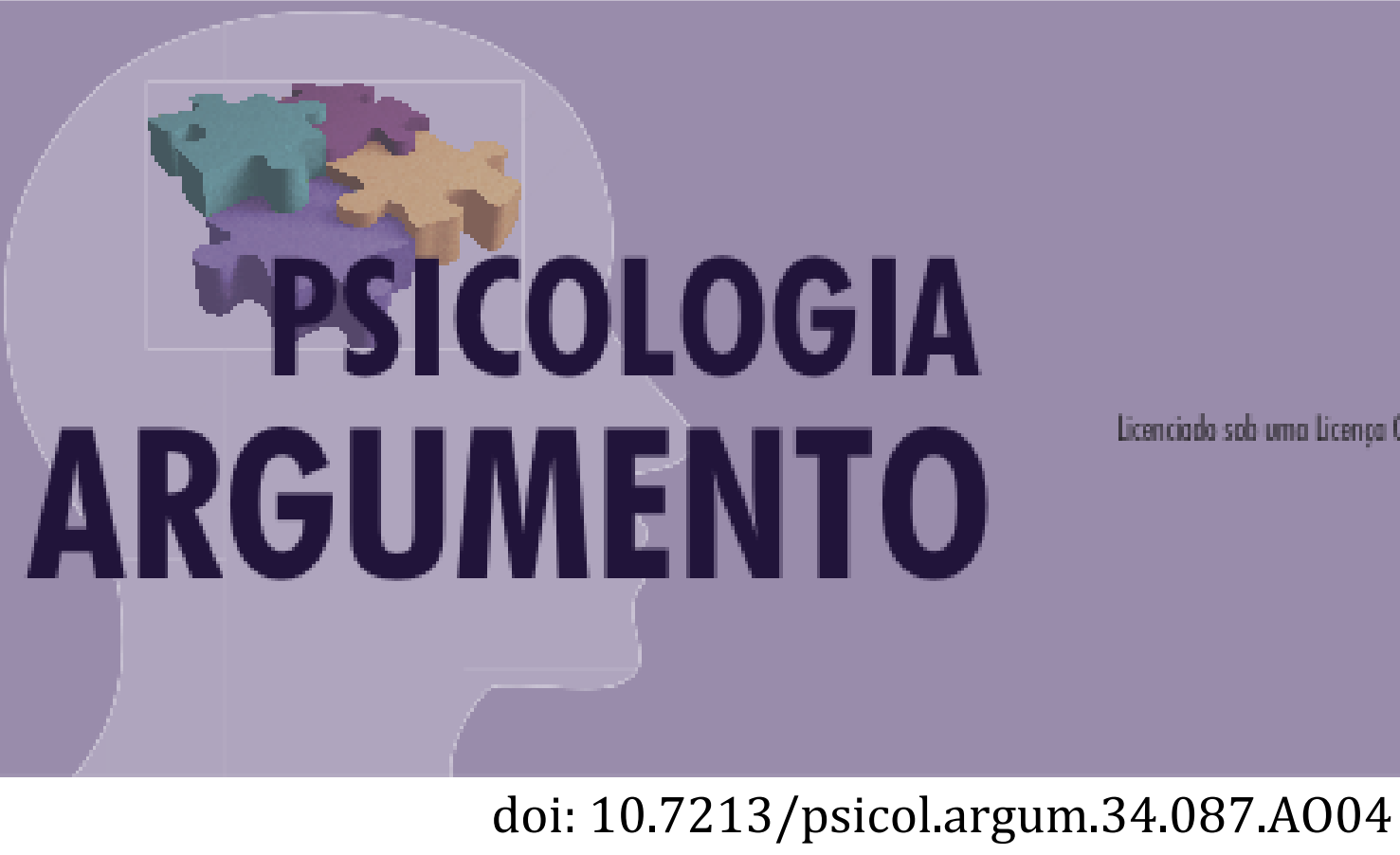

\title{
Liderança e gestão democrática na educação infantil
}

\section{Leadership and democratic management in early education}

Cloves Antonio de Amissis Amorim [a], Sirley Terezinha Filipak [b], Catarina Moro [c], Joaquim Francisco

Dias Setin [d].

[a] Doutorando em Educação pelo Programa de Pós Graduação em Educação da Pontifícia Universidade Católica do

Paraná. Docente do Curso de Psicologia (PUCPR), Curitiba, Paraná - Brasil e-mail: clovesamorim@hotmail

[b] Doutora em Educação pelo Programa de Pós-graduação em Educação da Pontifícia Universidade Católica do Paraná. Docente do Curso de Pedagogia e do Programa de Pós-graduação em Educação (PUCPR), Curitiba,

Paraná - Brasil. e-mail: sirley.filipak@pucpr.br

[c] Doutora em Educação pelo Programa de Pós-graduação em Educação da Universidade Federal do Paraná.

Docente do Curso de Pedagogia (UFPR), Curitiba, Paraná - Brasil. e-mail: moro.catarina@gmail.com

[d] Graduando em Licenciatura em Ciências Biológicas pela Pontifícia Universidade Católica do Paraná, egresso do Programa Institucional de Bolsas de iniciação a Docência (PIBID-PUCPR). Curitiba, Paraná, Brasil.

E-mail joaquimsetin@gmail.com 


\title{
Resumo
}

A experiência profissional dos gestores é fator influente na qualidade do atendimento na educação infantil. Esse estudo teve como objetivos realizar uma breve revisão bibliográfica da gestão da educação infantil no Brasil e analisar a práxis de formação continuada desenvolvida junto a gestores dos Centros Municipais de Educação Infantil (CMEIs). Participaram do estudo 180 gestores, todos do sexo feminino, em duas fases, no período de um ano letivo. Utilizou-se da metodologia da pesquisa-ação colaborativa e foram realizadas reuniões em grupos no Centro de Formação Continuada da Secretaria Municipal de Educação, divididos por núcleos regionais, com a apresentação e a discussão coletiva dos projetos realizados nos CMEIs. Os resultados indicaram que a gestão democrática na educação infantil demanda a compreensão da criança pequena como cidadão de direitos, bem como a própria concepção de gestão democrática. A educação infantil tem peculiaridades importantes, como organização do ambiente e planejamento das práticas educativas, incluindo o cuidado de rotinas. A revisão bibliográfica apontou para escassez na produção nacional específica de gestão educacional na educação infantil e múltiplas compreensões do significado de gestão democrática. Conclui-se que tem ocorrido avanços no campo da gestão democrática e que a participação da comunidade contribui para a transparência das decisões tomadas, mas ainda necessita ampliar o conceito de autonomia, bem como a participação das crianças. A superficialidade do conhecimento teórico sobre gestão democrática demanda formação continuada dos gestores e o permanente abandono do improviso no exercício da função.

Palavras-chave: Gestão, educação infantil, liderança.

\begin{abstract}
The professional experience of school managers is an influential factor in the quality of care in children's education. Objectives of this study: to carry out a brief bibliographical review of the management of early childhood education in Brazil and to analyze the praxis of continued-education developed with pedagogical teams of the Municipal Centers for Early Childhood Education (CMEI). A total of 180 female managers participated in the study; In two phases, in the period of one academic year. The method used was the Collaborative Action Research Methodolog; Meetings were held in groups at the Center for Continuing Education of the Municipal Education Department, divided by regional centers with the presentation and collective discussion of the projects carried out at the CMEI's. The results indicated that democratic management in early childhood education demands the understanding of the young child as a citizen of rights as well as the conception of democratic management. The early childhood education has important peculiarities such as organization of the environment and planning of routines. The literature review pointed to scarcity in the specific national production of educational management in early childhood education and multiple understandings of the meaning of democratic management. It is concluded that there have been advances in the field of democratic management, and that community participation contributes to the transparency of decisions taken, but still needs to expand the concept of autonomy as well as the participation of children. The superficiality of the theoretical knowledge about democratic management demands continuous formation of the managers and the permanent abandonment of the subterfuges in the exercise of educational function
\end{abstract}

Keywords: Management, early education, leadership.

\section{Introdução}

Esse artigo tem dois objetivos. O primeiro foi proceder uma breve, e não exaustiva, revisão da literatura sobre a gestão da educação infantil, haja vista que Campos (2012) informa que dentre mais de 700 fontes localizadas na Base de dados "Gestão Escolar" disponível na página da Fundação Carlos Chagas, entre 2001 e 2008, foram localizadas apenas 6 artigos, 4 teses e 14 dissertações, utilizando como busca o descritor "gestão da 
educação infantil". Acrescenta-se, ainda, que no Banco de Teses da Coordenação de Aperfeiçoamento de Pessoal de Nível Superior (CAPES), no período de 2009 a 2010, foram encontradas duas teses e quatro dissertações (Campos, 2012, p. 28). O segundo objetivo foi analisar uma proposta de formação continuada (na modalidade pesquisa-ação colaborativa) para gestores dos Centro Municipais de Educação Infantil (CMEIs), realizada na Secretaria Municipal de Educação da Prefeitura Municipal de Curitiba.

Nossa breve revisão teve como finalidade o conhecimento do campo e as produções mais representativas. Encontramos, em nossa revisão, dissertações que se ocupam dos Centros Municipais de Educação Infantil de Curitiba (Soczek, 2006 e Gomes, 2010), que permitiram um cotejamento com a nossa práxis junto aos gestores que participaram do curso.

Merecem destaque os livros Gestão e motivação em Educação Infantil, traduzido do inglês, de autoria de Lynn Marotz e Amy Lawson (2012), e Sociologia da infância e a formação de professores, organizado por Romilda T. Ens e Marynelma C. Garanhani (2013), particularmente o capítulo dedicado à formação continuada dos gestores de creches públicas, de autoria da professora Celia Maria Guimarães. Em 2015, a Rede Marista de Solidariedade publicou Avaliação "da" e "na" educação infantil: significando conceitos e práticas, destacando, no capítulo 5, a qualidade e a participação como princípios na gestão a serviço da defesa dos direitos das infâncias. Citamos essas três obras uma vez que revisões anteriores não identificaram livros específicos ou exclusivos de gestão da educação infantil.

Apesar das fontes encontradas, que a nosso ver é mínima frente à produção bibliográfica da gestão da Educação no geral, podemos afirmar a existência de uma lacuna. De acordo com Campos (2012, p. 28),

Essa lacuna é especialmente grave devido ao fato de que a gestão de creches e préescolas apresenta especificidades importantes, quando comparada a gestão de escolas que atende crianças acima de seis anos de idade, como: integrar o cuidado à Educação, uma vez que as crianças pequenas necessitam maior atenção por parte dos adultos; organizar ambientes que estejam de acordo com as necessidades das faixas etárias atendidas; planejar rotinas para o atendimento em turno integral (caso de muitas creches), manter uma relação próxima com as famílias. Assim, as instituições de educação infantil têm preocupações peculiares, que geram demandas bastante diversas das do Ensino Fundamental.

Figuram entre os artigos mais consultados os de autoria de Aguiar (2008), Aquino (2009), Garcia e Macedo (2011), Mello e Luz (2015). Contribuíram de forma substancial para o presente estudo o artigo A gestão democrática nas instituições de educação infantil: questões para pensar a formação de gestores, de autoria de Ligia Maria Leão de Aquino (2008/2009) e A importância da gestão na formação dos profissionais da educação infantil: respeito às diversidades, de autoria de Lucrecia Stringhetta Mello e Anízia Aparecida Nunes Luz (2015).

Num estudo que se propõe a contribuir com a formação de gestores, líderes democráticos na educação infantil, é relevante destacar a utilização dos termos administração $\mathrm{X}$ gestão. $\mathrm{O}$ primeiro aparece como uma perspectiva técnica, uma transposição das teorias de Administração para o mundo da escola; enquanto o termo gestão tem significado políti- 
co. De acordo com Lück (2006, p. 23), a gestão emerge para superar carências, entre elas, "[...] de referencial teórico-metodológico avançado para a organização do trabalho em educação".

Pereira (2007) recorre a Casassus (2002) para analisar a oposição entre os termos administração e gestão, destacando que a gestão educacional é um campo recente de estudos, que se constitui a partir da segunda metade do século XX. Afirma que:

O termo gestão educacional é mais adequado do que administração. A administração está atrelada a concepção taylorista/fordista de produção, tendo como uma de suas características a divisão do trabalho, portanto, a separação entre pensar e executar. Esse modelo se encaixa no regime político autoritário, em que a centralização das decisões faz com que os planejamentos sejam feitos em nível central, cabendo a escola a função de executora de um plano que foi elaborado alheio a ela. (Pereira, 2007, p. 19).

Primeiro propomo-nos a situar as bases legais da gestão democrática na educação infantil. Abordamos os Conselhos de CMEI como forma de excelência para operacionalizar a gestão democrática e a participação de todos os envolvidos (alinhando nossa perspectiva com os entendimentos e as proposições de Marcia Aguiar, 2008) e em seguida lançamos o foco de análise para a necessária participação das famílias e as estratégias de implementação dos parâmetros indicadores de qualidade. Finalmente, a apreciação da pesquisa-ação colaborativa desenvolvida com os gestores dos CMEIs. Por fim, indicamos alguns pontos necessários ao desenvolvimento do líder gestor para implementar coletivamente a gestão democrática nos centros Municipais de Educação.

\section{Educação infantil e a legislação}

As contingências sociais e econômicas advindas das mudanças de forma de produção na Europa e motivações religiosas, bem como a saída das mulheres para o trabalho fora do lar demandaram o atendimento de crianças em instituições especializadas.

De acordo com Flores e Tomazzetti (2012, p. 8),

As primeiras instituições públicas de educação infantil no Brasil datam de 1899 a partir da fundação do Instituto de Proteção e Assistência à Infância do Rio de Janeiro e da inauguração da creche da Companhia de Fiação e Tecidos Corcovado (RJ) que se constituiu como marco, pois é a primeira creche brasileira para filhas de operários que se tem registro. As creches assim denominadas eram consideradas como asilo para a primeira infância, estas foram criadas para atender filhos de mães trabalhadoras, onde predominava o caráter assistencialista, priorizando o atendimento das crianças social e economicamente desfavorecidas.

As creches têm sua origem para atender às crianças pobres, aos filhos de operários, ou melhor, de operárias. Mulheres trabalhadoras precisavam de um lugar para deixar seus filhos enquanto trabalhavam. Por outro lado, surge, por influência alemã, o Kindergarten, o jardim de infância para as classes econômicas que pudessem arcar com os custos. Esses jardins de infância apresentavam o termo pedagógico para serem diferenciados das creches marcadamente assistencialistas. 
Foi somente na constituição Federal de 1988 que se estabeleceu o atendimento de creches e pré-escolas às crianças de zero a seis anos como dever do Estado. Soczek (2006), Ariosi (2010) e Monção (2013) são unânimes em apontar o artigo 208, inciso IV, da Constituição Federal de 1988, e também o artigo 7, inciso XXV, que tratam a educação infantil como um direito dos trabalhadores - homens e mulheres, na zona rural e urbana, “[...] a assistência gratuita aos filhos e dependentes desde o nascimento até os seis anos de idade em Creches e Pré-escolas".

Soczek (2006) destaca ainda outra determinação da Constituição, que acrescentou uma diferença significativa na forma de manutenção da educação infantil, sendo responsabilidade do Município, com a cooperação técnica e financeira da União e do Estado. Aponta, ainda, a corresponsabilização financeira e técnica entre os entes federados.

De acordo com Ariosi (2010), as instituições de educação infantil tratadas como instituições educacionais levaram à incorporação da educação infantil ao sistema regular de ensino. Em geral, estavam vinculadas aos órgãos assistenciais e de saúde.

Em 1990, O Estatuto da Criança e do Adolescente (ECA), Lei Federal n. ${ }^{\circ} 8.069$, de 13 de julho, reconhece e reafirma o direito à educação como direito da criança e não mais da mãe trabalhadora. Essa perspectiva muda a concepção de educação compensatória para a convicção de que a educação infantil é uma necessidade para que ocorra o pleno desenvolvimento do indivíduo (Ariosi, 2010).

A Lei de Diretrizes e Bases da Educação Nacional (LDBEN), Lei n. ${ }^{\circ}$ 9394, promulgada em 20 de dezembro de 1996, reconhece a educação infantil como a primeira etapa da educação básica, representando um importante dispositivo para reforçar e garantir os direitos sociais das crianças. Monção (2013) dá destaque ao artigo 29 da LDBEN, segundo o qual a pré-escola e a creche "[...] tem como finalidade o desenvolvimento integral da criança até seis anos de idade, em seus aspectos físico, psicológico, intelectual e social, complementando a ação da família e da sociedade". Destaca ainda a autora supracitada que "A constituição, o ECA e a LDBEN-1996, juntamente com as pesquisas na área da Educação infantil desenvolvidas nas três últimas décadas, influenciaram contundentemente o delineamento das políticas públicas para a educação da primeira infância [...]" (Monção, 2013, p. 14).

A inserção das creches nos sistemas de ensino, integrando o cuidado e a educação numa ação compartilhada com a família, revela a função socializadora da Educação Infantil. Desde a década de 90, o Ministério da Educação (MEC) produz documentos para subsidiar as ações e a qualidade do atendimento realizado pela Educação infantil. No quadro 1, a seguir, tem-se uma listagem de algumas dessas publicações, com a informação sobre o ano em que foram editadas ${ }^{1}$.

\footnotetext{
${ }^{1}$ Tais publicações se encontravam disponíveis na página web do Ministério da Educação, até o mês de outubro de 2016, no link:

http://portal.mec.gov.br/index.php?option=com_content\&view=article\&id=12579\%3Aeducacaoinfantil\&Itemid=859.
} 


\section{Quadro 1- Documentos Nacionais para a Educação Infantil}

\begin{tabular}{|c|c|}
\hline 1995 & Critérios para um Atendimento em Creches que Respeite os Direitos Fundamentais das Crianças \\
\hline 1998 & $\begin{array}{l}\text { Subsídios para Credenciamento e o Funcionamento das Instituições de Educação Infantil (material } \\
\text { suspenso e substituído pelo de Política Nacional, de 2005) }\end{array}$ \\
\hline 1998 & Referencial Curricular Nacional para a Educação Infantil - RCNEI \\
\hline 2002 & $\begin{array}{l}\text { Integração das instituições de Educação Infantil aos sistemas de ensino: um estudo de caso de } \\
\text { cinco municípios que assumiram desafios e realizaram conquistas }\end{array}$ \\
\hline 2005 & Política Nacional de Educação Infantil: pelo direito das crianças de zero a seis anos à Educação \\
\hline 2006 & $\begin{array}{l}\text { Parâmetros Nacionais de Qualidade para a Educação Infantil e os Parâmetros Básicos de } \\
\text { Infraestrutura dos Estabelecimentos de Educação Infantil }\end{array}$ \\
\hline 2009 & $\begin{array}{l}\text { Orientações sobre convênios entre secretarias municipais de educação e instituições comunitárias, } \\
\text { confessionais ou filantrópicas sem fins lucrativos para a oferta de educação infantil }\end{array}$ \\
\hline 2009 & Política de educação infantil no Brasil: Relatório de avaliação \\
\hline 2009 & Indicadores da Qualidade na Educação Infantil \\
\hline 2011 & $\begin{array}{l}\text { Diretrizes Curriculares Nacionais para a Educação Infantil (publicação com base na Resolução } n^{\circ} \\
5 / 09 \text {, do Conselho Nacional de Educação) }\end{array}$ \\
\hline 2012 & Educação Infantil e Práticas Promotoras de Igualdade Racial \\
\hline 2012 & Educação Infantil, Igualdade Racial e Diversidade: aspectos políticos, jurídicos, conceituais \\
\hline 2012 & Brinquedos e Brincadeiras de Creche \\
\hline 2012 & Oferta e demanda de Educação Infantil no Campo \\
\hline 2012 & Educação Infantil: Subsídios para construção de uma sistemática de avaliação \\
\hline 2013 & Relatório do Monitoramento do Uso dos Indicadores da Qualidade na Educação Infantil \\
\hline 2013 & Monitoramento do Uso dos Indicadores da Qualidade na Educação Infantil - Resumo Executivo \\
\hline 2013 & Estudo sobre a organização dos espaços internos das unidades do Proinfância (relatórios) \\
\hline 2013 & $\begin{array}{l}\text { Análise das discrepâncias entre as conceituações de educação infantil do INEP e IBGE, sugestões } \\
\text { e subsídios para maior e mais eficiente divulgação dos dados }\end{array}$ \\
\hline 2014 & Instrumento de acompanhamento da expansão da oferta da educação infantil, urbana e rural \\
\hline 2014 & Educação Infantil do campo \\
\hline 2015 & Educação Infantil em tempo integral \\
\hline 2015 & Diretrizes em Ação \\
\hline 2014 & Educação Infantil - Os desafios estão postos e o que estamos fazendo? \\
\hline
\end{tabular}




\begin{tabular}{|l|l|}
\hline 2015 & Implementação do Proinfância no Estado do Rio Grande do Sul \\
\hline 2015 & Avaliação em Educação Infantil a partir da Avaliação de Contexto \\
\hline 2015 & Território do Brincar: diálogo com escolas (documentário e PDF) \\
\hline 2016 & Literatura na Educação Infantil: acervos, espaços e mediações \\
\hline
\end{tabular}

FONTE: Sítio do MEC, consultado em abril de 2016, complementado de Moro (2013).

Apresentada a legislação nacional sobre a educação infantil, podemos abordar a gestão democrática como mecanismo de excelência que contempla o pensar e o fazer, em oposição ao termo administração, que tem como uma de suas características fundantes a divisão entre planejar e executar.

Para Moro (2013), com esses materiais, o MEC buscava subsidiar o trabalho na etapa da educação infantil " [...] na instância dos sistemas de ensino (sejam municipais ou estaduais) e também das instituições, servindo como base para acompanhamento, controle, supervisão dos serviços ofertados e para efetivação de práticas pedagógicas que respeitem necessidades, direitos e interesses das crianças" (p. 57).

\section{Gestão democrática}

A Constituição Federal de 1988 retrata os desejos por democracia da sociedade brasileira, em seu art. 206, que define o princípio da gestão democrática nas instituições públicas de ensino como princípio da educação nacional (Adrião \& Camargo, 2001).

A Constituição faz uma escolha por um regime normativo e político, plural e descentralizado, no qual se cruzam novos mecanismos de participação social com um modelo institucional cooperativo, que amplia o número de sujeitos políticos capazes de tomar decisões. Por isso mesmo, a cooperação exige entendimento mútuo entre os entes federativos e a participação supõe a abertura de novas arenas públicas de deliberação e mesmo de decisão (Cury, 2010).

A Lei de Diretrizes e Bases da Educação Nacional, LDBEN n. 9.394/96, reitera os princípios constitucionais, mas também destaca a importância da articulação entre comunidade e a escola, estabelecendo, no Art. 12, Parágrafo VI, que os estabelecimentos de ensino, respeitadas as normas comuns e as do seu sistema de ensino, terão a incumbência de articular-se com as famílias e a comunidade, criando processos de integração da sociedade com a escola. Esse artigo reforça a importância da participação da comunidade na gestão escolar. Todavia, essa participação não pode ser encarada como um mecanismo de controle, mas, sim, de responsabilidade pelo processo pedagógico e de formação do cidadão e da própria sociedade (Paro, 2000).

O Caderno 5 do MEC - Conselho escolar, gestão democrática da educação e escolha do diretor - traz reflexões quanto à importância da participação, afirmando que ela se constitui em uma das bandeiras fundamentais a serem implementadas pelos diferentes atores que constroem o cotidiano escolar (p. 15). Esse mesmo caderno, na página 26, define participação como:

Processo complexo que envolve vários cenários e múltiplas possibilidades de organização. Ou seja, não existe apenas uma forma ou lógica de participação: há dinâmicas que 
se caracterizam por um processo de pequena participação e outras que se caracterizam por efetivar processos em que se busca compartilhar as ações e as tomadas de decisão por meio do trabalho coletivo, envolvendo os diferentes segmentos da comunidade escolar. Isso quer dizer que alguns processos chamados de participação não garantem o compartilhamento das decisões e do poder, configurando-se como mecanismo legitimador de decisões já tomadas centralmente.

Para que ocorra a participação de fato, são necessários cuidados com esses mecanismos legitimadores de poder, especialmente pela tendência de alguns gestores das escolas de conduzirem todas as ações, sem solicitarem previamente as sugestões dos conselheiros.

Mas a participação ainda é um desafio e exige formação e quem sabe se começarmos com essa geração que está nas escolas, possamos ver uma participação de fato, conforme Luiz (2010, p. 60):

A formação para uma participação que signifique "ser parte, fazer parte e tomar parte", três elos de uma concepção que vai muito além de meras consultas sobre eventuais temas que são apresentados aos pais dos alunos, ocorre no interior do amplo movimento que se deseja democrático na sociedade brasileira, nos limites da reforma do Estado e das novas demandas do capital transnacional que se impõem aos países como uma nova forma de colonização econômica

O sistema de ensino gerido democraticamente é aquele no qual as decisões (técnicas e financeiras) são fruto de amplas discussões com a comunidade e com profissionais envolvidos dos diferentes setores e níveis da educação.

Assim, é necessária a superação do modelo tradicional de gestão pública, no qual ocorre a concentração de autoridade nas mãos de uma só pessoa, o diretor, que se torna o responsável por todas as decisões, mas precisa caminhar para uma forma de gestão que propicie a distribuição da autoridade de maneira mais adequada a atingir os objetivos identificados com a transformação social. Superar esse modelo é um grande desafio frente aos processos históricos e às vivências de cada comunidade escolar.

Essa concepção traz um novo modelo de gestão, pois pressupõe a participação democrática, entendida a partir da possibilidade de efetivo envolvimento, em que são necessários o diálogo e a tomada de decisão coletiva, abrindo mão de interesses pessoais para atingir objetivos comuns.

[...] A gestão implica um ou mais interlocutores com os quais se dialoga pela arte de interrogar e pela paciência em buscar respostas que possam auxiliar no governo da educação, segundo a justiça. Nesta perspectiva, a gestão implica o diálogo como forma superior de encontro das pessoas e solução dos conflitos. (Cury, 2010, p. 1)

O princípio da gestão democrática está contido também na Lei de Diretrizes e Bases da Educação Nacional de 1996, no Plano Nacional da Educação aprovado em 2001 e também no aprovado em 2014. Cury esclarece que: 
A gestão democrática, enquanto temática histórica nos move em direção contrária àquela mais difundida em nossa trajetória política, em que os gestores se pautam ora por um movimento paternalista, ora por uma relação propriamente autoritária. Paternalismo e suas variantes, autoritarismo e congêneres são formas de pensar e agir sobre o outro não reconhecido como igual. (Cury, 2010, p. 1)

A superação do movimento paternalista e do autoritarismo exige: autoavaliação constante e práticas que favoreçam a cooperação e o respeito aos outros como iguais. Alguns princípios indicados pelo Plano Nacional de Educação (PNE) orientam algumas ações para uma prática democrática: "I - participação dos profissionais da educação na elaboração do projeto pedagógico da escola; II - participação das comunidades escolar e local em conselhos escolares ou equivalentes". Esses itens favorecem a autonomia e a participação da comunidade escolar na gestão da escola: "A gestão democrática da educação é, ao mesmo tempo, transparência e impessoalidade, autonomia e participação, liderança e trabalho coletivo, representatividade e competência a gestão democrática é uma gestão de autoridade compartilhada". (Cury, 2010, p. 2)

A gestão democrática pressupõe a participação efetiva de todos os segmentos da comunidade escolar; a garantia de pleno acesso às informações referentes aos assuntos escolares a todas as pessoas da escola, pedagogos, professores, funcionários, educadores, alunos e familiares; a garantia do respeito à vontade da maioria, possibilitando o comprometimento dos envolvidos, decisões, mecanismo de controle, participação essa que traz responsabilidade e sentimento de pertença.

\section{Gestão democrática de CMEIs}

Seguindo o que prescreve a LDBEN, a Câmara de Educação Básica do Conselho Nacional de Educação aprovou as Diretrizes Curriculares Nacionais para a Educação Infantil, em 1999, e em 2009 a mesma Câmara aprova as diretrizes em vigor, também com caráter mandatório para todos os sistemas municipais e ou estaduais de educação. As diretrizes são claras ao definir, em seu artigo sétimo, que a proposta pedagógica de cada instituição educativa assegure o cumprimento pleno da sua função sociopolítica e pedagógica, nos seguintes termos:

I - oferecendo condições e recursos para que as crianças usufruam seus direitos civis, humanos e sociais;

II - assumindo a responsabilidade de compartilhar e complementar a educação e cuidado das crianças com as famílias;

III - possibilitando tanto a convivência entre crianças e entre adultos e crianças quanto a ampliação de saberes e conhecimentos de diferentes naturezas;

IV - promovendo a igualdade de oportunidades educacionais entre as crianças de diferentes classes sociais no que se refere ao acesso a bens culturais e às possibilidades de vivência da infância;

$\mathrm{V}$ - construindo novas formas de sociabilidade e de subjetividade comprometidas com a ludicidade, a democracia, a sustentabilidade do planeta e com o rompimento de relações de dominação etária, socioeconômica, étnico-racial, de gênero, regional, linguística e religiosa. (Brasil, 2009, p. 2). 
As DCNEI vigentes reiteram também: "i) a criança como centro do planejamento curricular; ii) a brincadeira e as interações como eixos do trabalho pedagógico e os iii) princípios éticos, políticos e estéticos com fundamentais no processo educativo". A melhoria na educação, em especial no processo de gestão democrática, que rompe como o modelo centralizado, não acontece apenas por meio de leis e/ou decretos, tratando-se, em vez disso, de um processo longo, de construção coletiva. Por isso, o conselho CMEI deve se tornar um espaço de participação da comunidade na gestão da escola pública.

Participar da gestão democrática do CMEI significa que todos sentem-se e efetivamente são partícipes do sucesso ou do fracasso do Centro de Educação Infantil em todos os seus aspectos: físico, educativo, cultural e político.

Quais as possibilidades e limites para que os gestores no desempenho de suas funções favoreçam a gestão democrática nos centros de Educação Infantil? Uma gestão democrática precisa da participação ativa da comunidade, no momento de partilhar o poder e tomar uma decisão. Implica a efetivação de novos processos de organização e gestão baseados em uma dinâmica que favoreça os processos coletivos e participativos de decisão. Nesse sentido, a participação constitui uma das bandeiras fundamentais a serem implementadas pelas diferentes pessoas que constroem o cotidiano escolar.

\section{Gestão democrática na Educação Infantil - conselhos de CMEIs}

Uma das formas de efetivar essa participação é por meio da candidatura a uma vaga no conselho de CMEI. A Constituição Federal de 1988, no Capítulo que trata da Educação, apresenta no seu Artigo 206 os princípios que devem pautar o ensino nos estabelecimentos da rede pública. Dentre esses princípios, destaca-se a "gestão democrática". Segundo Gadotti (2000, p. 67), “[...] a participação e a democratização num sistema público de ensino é uma forma prática de formação para a cidadania que, por sua vez, é um dos pressupostos da gestão democrática". Essa formação adquire-se na participação no processo de tomada de decisões. A criação dos conselhos de CMEIs representa uma parte desse processo.

Nessa direção, a implantação dos Conselhos nos Centros Municipais de Educação Infantil - Conselhos dos CMEIs - contribui para que esse espaço de participação efetivese e que se desenvolva uma gestão democrática. Na defesa do princípio democrático da participação ativa, os Parâmetros e Indicadores de Qualidade para a Educação Infantil de Curitiba reafirmam que:

[...] a responsabilidade em tomar decisões de ordem pedagógica, administrativa e financeira dentro da instituição não se encerra em uma única pessoa, mas envolve o Conselho, com a representatividade de diferentes segmentos que compõem o coletivo da educação infantil: profissionais, familiares e comunidade. Conferem ainda que, além desses segmentos, também as crianças devem ser convidadas a identificar necessidades, discutir, avaliar e participar da tomada de decisões no processo da educação infantil. (Curitiba, 2011, p. 9)

Para garantir a tomada de decisões de forma democrática, os Conselhos de CMEI são constituídos de acordo com o princípio da representatividade, assegurando o equilíbrio entre os representantes dos profissionais da unidade e os representantes dos pais ou res- 
ponsáveis pelas crianças, da unidade de saúde e de instituições comunitárias. (Curitiba, 2011, p. 15)

Essa concepção vem ao encontro das orientações e concepções teóricas do Ministério da Educação quando define os Conselhos escolares como:

[...] órgãos colegiados compostos por representantes das comunidades escolar e local, que têm como atribuição deliberar sobre questões político-pedagógicas, administrativas, financeiras, no âmbito da escola. [...] Eles representam as comunidades escolares e locais, atuando em conjunto e definindo caminhos para tomar as deliberações que são de sua responsabilidade. Representam, assim, um lugar de participação e decisão, um espaço de discussão, negociação e encaminhamento das demandas educacionais, possibilitando a participação social e promovendo a gestão democrática. São, enfim, uma instância de discussão, acompanhamento e deliberação, na qual se busca incentivar uma cultura democrática, substituindo a cultura patrimonialista pela cultura participativa e cidadã.

(Brasil, 2004, p. 34)

Nesse contexto, o papel do Conselho de CMEI é o de ser órgão consultivo, deliberativo e de mobilização mais importante do processo de gestão democrática, não como instrumento de controle externo, como eventualmente ocorre, mas como um parceiro de todas as atividades que se desenvolvem no interior do CMEI. Sua participação, nesse processo, precisa estar ligada, prioritariamente, à essência do trabalho escolar.

O Conselho de CMEI traz para si o propósito de discutir e definir o tipo de educação a ser desenvolvido na escola, para torná-la uma prática democrática comprometida com a qualidade socialmente referenciada. Sendo assim, sabendo onde se deseja chegar e que tipo de trabalho se deseja desenvolver, o Conselho de CMEI pode iniciar uma ação consciente e ativa na escola.

Segundo o Manual dos Conselhos de CMEIS, esses apresentam como objetivos:

I. Estabelecer espaço permanente de reflexão e construção do trabalho pedagógico, tendo como premissa a importância da participação de todos os segmentos da comunidade educativa no desenvolvimento integral das crianças. II. Fortalecer as condições de participação para que todos os segmentos que compõem a comunidade educativa se responsabilizem de forma efetiva pelas decisões inerentes à gestão do CMEI. III. Possibilitar maior participação das famílias nas ações pedagógicas, considerando a importância dela no desenvolvimento do Plano de Ação Anual. IV. Promover condições para garantir às crianças matriculadas educação de qualidade, conforme os Parâmetros e Indicadores de Qualidade para a Educação Infantil do Município. V. Possibilitar que as crianças desenvolvam sua autonomia e identidade a partir da oportunidade de expressar seus sentimentos, de participar de decisões e de assumir responsabilidades conforme suas possibilidades. (Curitiba, 2011, p. 11)

Além dos objetivos estabelecidos, cada Conselho de CMEI pode, se julgar necessário, elaborar um regimento interno estabelecendo normas relativas à convocação das reuniões ordinárias e extraordinárias, à eleição de seus membros, entre outros. "É no Conselho que os problemas da gestão escolar devem ser discutidos, é nele que as reivindicações educativas serão analisadas para, se for o caso e, dependendo dos encaminhamentos e da 
votação em plenária, serem aprovadas e remetidas para o corpo diretivo da escola que se encarregará de colocá-las em prática" (Gadotti, 2000, p. 72).

A busca da gestão democrática inclui, necessariamente, a ampla participação dos representantes dos diferentes segmentos da escola nas decisões/ações administrativopedagógicas ali desenvolvidas.

Os Conselhos de CMEI representam a comunidade escolar e a local no enfrentamento de desafios educativos e de problemas sociais, contribuindo para a construção de uma sociedade mais justa e igualitária. Dentre esses desafios, poderíamos citar a garantia de direitos de crianças e adolescentes, inclusive o direito de exercitar a cidadania desde cedo.

De acordo com o Referencial Curricular Nacional para a Educação Infantil (Brasil, 2010), a criança como todo ser humano é um sujeito social e histórico e faz parte de uma organização familiar que está inserida em uma sociedade, com uma determinada cultura, em um determinado momento histórico. É profundamente marcada pelo meio social em que se desenvolve, mas também o marca.

Assim, é de responsabilidade do gestor que a instituição de educação infantil torne acessível a todas as crianças que a frequentam, indiscriminadamente, elementos de cultura que enriquecem o seu desenvolvimento e inserção social, estimulando a participação em decisões quanto ao encaminhamento das atividades e dos espaços do CMEI. Se a criança conviver num ambiente cooperativo e democrático no CMEI, que favoreça trocas sociais por reciprocidade, no qual seja respeitada pelo adulto e participe ativamente dos processos de tomada de decisões, por hipótese, ela tenderá a desenvolver uma atitude mais cidadã e autônoma.

A participação e a cooperação ocorrem necessariamente a partir da convivência da criança com seus pares e com os adultos e com o diálogo, que é fundamental a uma unidade de ensino e cuidado que se pretenda democrática. A importância do diálogo é sintetizada por Moreira ao ouvir a opinião de especialistas na área: “[...] o diálogo é visto como instrumento de ensino, de mediação entre grupos distintos, de democratização da escola e da sociedade, de criação de consensos culturais e cognitivos, de eliminação de barreiras entre as diferenças". (Moreira, 2002, p. 4)

Então é fundamental a cada CMEI abrir espaços para que as crianças conversem entre si, levantando pontos a serem melhorados nos espaços e nas atividades a serem desenvolvidas.

Para efetivação de seus objetivos, as propostas pedagógicas das instituições de Educação Infantil deverão prever condições para a participação, o diálogo e a escuta cotidiana das famílias, o respeito e a valorização de suas formas de organização, o estabelecimento de uma relação efetiva com a comunidade local e de mecanismos que garantam a gestão democrática e a consideração dos saberes da comunidade, o reconhecimento das especificidades etárias, das singularidades individuais e coletivas das crianças, promovendo interações entre crianças de mesma idade e crianças de diferentes idades. (Brasil, 2010, p. 19).

$\mathrm{Na}$ gestão democrática, todos, inclusive as crianças, identificam necessidades, discutem, avaliam e participam da tomada de decisões no processo da educação infantil que, dada sua complexidade, exige uma dinâmica intersetorial, a integração de ações relacionadas à saúde, à assistência social e à cultura, e a articulação com Conselhos Tutelares, Associação de Moradores e Rede de Proteção à Criança e ao Adolescente em situação de risco para a violência. 
A ação compartilhada é um importante eixo de trabalho na educação infantil com as famílias para a condução da educação das crianças. A escolha de estratégias de interação e de como aproximar as famílias da instituição é definida pela equipe de profissionais, considerando a opinião dos familiares, na discussão da proposta pedagógica em cada unidade, no sentido de estabelecer uma relação de complementaridade na educação das crianças entre a instituição de educação infantil e as famílias. Ações educativas pautadas em relações democráticas são fundamentais para que os diferentes atores envolvidos nesse processo conheçam a realidade social, compartilhem problemas, provoquem reflexões e procurem repensar modalidades de atendimento que respondam aos direitos das crianças e famílias à educação infantil de qualidade.

A educação pública municipal de Curitiba vem trabalhando pelo exercício e pela construção da democracia participativa, com o objetivo de aproximar a comunidade dos projetos pedagógicos e, assim, garantir o direito do cidadão de afirmar os interesses coletivos. Para tanto, a implantação dos Conselhos nos Centros Municipais de Educação Infantil - Conselhos dos CMEIs - contribui para que esse espaço de participação efetive-se e que se desenvolva uma gestão democrática.

Na defesa do princípio democrático da participação ativa, os Parâmetros e Indicadores de Qualidade para a Educação Infantil de Curitiba reafirmam que a responsabilidade em tomar decisões de ordem pedagógica, administrativa e financeira dentro da instituição não se encerra em uma única pessoa, mas envolve o Conselho, com a representatividade de diferentes segmentos que compõem o coletivo da educação infantil: profissionais, familiares e comunidade. Conferem ainda que, além desses segmentos, também as crianças devem ser convidadas a identificar necessidades, discutir, avaliar e participar da tomada de decisões no processo da educação infantil.

\section{Metodologia}

Participaram desse estudo 180 diretores e pedagogos que atuam nos Centros Municipais de Educação Infantil. Todos foram convidados a participar de um projeto de desenvolvimento do papel de líder gestor para a Educação Infantil.

O encaminho metodológico foi o da pesquisa-ação (Elliott, 1997; Tripp, 2005; Yuni e Urbano, 2005; Molina, 2007; Kemmis e Wilkinson, 2011), tendo como característica principal o conhecimento da realidade para modificá-la. De acordo com Ghedin e Franco (2011), em trabalhos de pesquisa-ação no Brasil podem observar-se três conceituações diferentes, sendo que, de acordo com essas três classificações, o nosso estudo pode ser denominado de pesquisa-ação colaborativa.

Quando a busca de transformação é solicitada pelo grupo de referência da equipe de pesquisadores, a pesquisa tem sido conceituada como pesquisa ação colaborativa. Nela, a função do pesquisador é integrar-se e conferir um enfoque científico a um processo de mudança a anteriormente desencadeado pelos sujeitos do grupo. (Ghedin e Franco, 2011, p. 213)

O primeiro procedimento foi o planejamento com os núcleos regionais, em reuniões com técnicos da Secretaria Municipal e a escolha de um voluntário para apresentar seu projeto para análise e discussão coletiva, realizando, em seguida, reflexões coletivas e, por 
último, replanejamento das ações a serem implementadas. Para subsidiar as ações, foi proposta a implementação de dois projetos institucionais: 1) Olhe para mim com ternura e 2) A comunidade e os parâmetros indicadores de qualidade.

Foram realizadas reuniões com os diretores e pedagogos dos CMEIs dos diferentes núcleos regionais, coordenadas por um dos autores, no Centro de Capacitação da Secretaria Municipal de Educação. Após contatos com as técnicas do Departamento de Educação Infantil, os projetos foram apresentados na sua primeira fase, apontando as dificuldades, os êxitos vividos e os desafios identificados. Coletivamente, o grupo elencava alternativas de encaminhamentos. No segundo semestre, os mesmos grupos retomaram os encaminhamentos decididos nos encontros anteriores e avaliaram o alcance ou não das metas e, em especial, a atuação dos gestores com o Conselho do CMEI ou em especial a motivação para se instalar o Conselho.

\section{Considerações Finais}

A primeira constatação dos participantes do projeto vem ao encontro da recomendação de Malta (2012):

Recomenda-se às equipes gestoras (diretores e coordenadores) das instituições de Educação Infantil que reforcem o papel do Conselho Escolar e garantam que as decisões sejam tomadas no âmbito do colegiado; estimulem a participação das famílias e da comunidade na gestão da unidade.

Por outro lado, a concepção da criança como cidadão de direitos e a educação infantil como direito ainda está em vias de se constituir. Talvez o hibridismo de práticas gerenciais e a busca de gestão democrática possa ser um indicativo desse processo em andamento.

De acordo com Wendler (2012), 97\% dos CMEIs de Curitiba implantaram Conselhos Escolares em suas unidades. Segundo a autora, pode-se verificar que para a garantia da "democratização da gestão", nos documentos produzidos pela Secretaria Municipal de Educação (SME), são citados os Conselhos de CMEI, que efetivam suas ações por meio da atuação de colegiados.

Outra constatação dos participantes foi que a gestão democrática implica em que haja liberdade para que todos os participantes da instituição proponham, sugiram, dividam o poder de controlar a autoridade, de decidir e executar o projeto pedagógico.

Os participantes constataram também que a gestão democrática implica em que haja liberdade para que todos proponham, sugiram, dividam o poder de controlar a autoridade, de decidir e de executar o projeto pedagógico. Em geral, nos discursos dos gestores, aparecem as dificuldades em manejar as tensões normais e esperadas em grupos democráti$\cos$.

Podemos hipotetizar que a ausência de representatividade do gestor, à medida que é investido no cargo por indicação e não por eleição, possa fragilizar o processo de condução, em especial, nos momentos de tensões. Inclusive, Malta (2012, p. 65) afirma que "[...] a figura do diretor é central no funcionamento da instituição e a maior ou menor eficácia do trabalho educativo realizado depende da sua atuação". 
Malta (2012, p. 66) também apresenta a pesquisa Liderança Eficaz na Educação Infantil, realizada na Universidade de Londres, na qual destaca que a presença de uma liderança forte e a pouca rotatividade de funcionários têm influência na qualidade das instituições de Educação Infantil. Dessa pesquisa, podem ser listadas categorias de práticas de lideranças que têm como foco o ensino e a aprendizagem e devem ser considerados na formação dos líderes, entre elas, citamos algumas:

- Identificação e articulação de uma visão coletiva, especialmente em relação à Pedagogia e ao currículo;

- Garantia do compartilhamento da compreensão e dos objetivos da instituição;

- Compromisso com a continuidade e com o desenvolvimento profissional;

- Acompanhamento e avaliação prática, mediante um diálogo que promove a colaboração e envolvimento de todos;

- Impulso e facilitação de parcerias com pais e comunidade.

Após os dois momentos de formação, um em cada semestre, com duração de 20 horas cada, os participantes concordaram que investir na construção de relacionamentos interpessoais, pautando sempre pelo diálogo, conforme proposto por Cury (2010, p. 1), é uma estratégia, um exercício de liderança democrática. Também foi possível abstrairmos que a aprendizagem de adultos pode beneficiar-se com as propostas de Placco e Souza (2006, p. 23) quando apresentam os princípios norteadores que podemos considerar nas ações de formação continuada: 1) a aprendizagem do adulto decorre de uma construção grupal; 2) A aprendizagem se dá a partir do confronto e do aprofundamento das ideias; 3 ) O processo de aprendizagem é singular e envolve escolha deliberada [...]; 4) $\mathrm{O}$ ponto de partida para o conhecimento é a experiência que acumulamos.

As atividades realizadas com os gestores reforçaram a sugestão de Mello (2008) ao propor a criação de um grupo de discussão como espaço para a reflexão sobre práticas vivenciadas no cotidiano da gestão para se compartilhar os saberes próprios do exercício da gestão. A formação e o apoio aos educadores também foi apontado por Monção (2013, p. 42) ao indicar três aspectos indissociáveis que configuram os desafios contemporâneos para a implantação de políticas públicas e práticas de educação infantil:

A criança como centro do processo educativo; a parceria com as famílias no compartilhamento da educação e do cuidado das crianças pequenas na constituição da gestão democrática; e a formação e apoio permanente aos profissionais para atuarem em creches e pré-escolas.

Concluímos reforçando o papel dos Conselhos de CMEI, ou seja, proteger os gestores de decisões personalizadas e ou autoritárias. O permanente esforço para garantir a participação das famílias e das crianças além do processo de preenchimento dos indicadores de qualidade poderá promover uma cultura de participação cotidiana das famílias. 


\section{Referências}

Adrião, Thereza; Camargo, Rubens Barbosa de (2001). A gestão democrática na Constituição Federal de 1988. In: Oliveira, Romualdo Portela; Adrião, Thereza. (Org.). Gestão, financiamento e direito à educação: análise da $L D B$ e da Constituição Federal. São Paulo: Editora Xamã.

Aguiar, Marcia Angela da S. (2008) Gestão da educação básica e o fortalecimento dos conselhos escolares. Educar em Revista. n.31, p.129-144

Aquino, Ligia Maria Leão De. (2009) A gestão democrática nas instituições de educação infantil: questões para pensar a formação de gestores. In: Educação em Foco, vol13, n.2, p.251-268

Ariosi, Cinthia Magda Fernandes (2010). Organização e gestão democrática na escola pública de educação infantil: análise dos limites e perspectivas nas realidades brasileira e italiana. Tese de Doutorado. Programa de Pós-graduação em Educação, da Faculdade de Filosofia e Ciências da Universidade Paulista Júlio de Mesquita Filho, Campus Marília. Marília - SP.

Brasil (1988). Constituição da República Federativa do Brasil: promulgada em 5 de outubro de 1988. Recuperado em 12 de Abr. de 2013 de <www.mec.gov.br/legis/default.shtm>

Brasil (1996) Lei n.o 9.394/96 de 20 de dezembro de 1996. Lei de Diretrizes e Bases da Educação Nacional: Recuperado em 12 de Abr. de 2013 de <www.mec.gov.br/legis/default.shtm>.

Brasil (2004). Ministério da Educação. Secretaria de Educação Básica, Programa Nacional de Fortalecimento dos Conselhos Escolares, cadernos, 1, 4 e 5.

Brasil (2010) Resolução n. 5 de 17 de dezembro de 2009. Ministério da Educação. Secretaria de Educação Básica. Diretrizes curriculares nacionais para a educação infantil / Secretaria de Educação Básica. - Brasília: MEC, Secretaria de Educação Básica, 2010.

Campos, Maria Malta (2012). A Gestão da Educação Infantil no Brasil: Relatório Final. São Paulo: Fundação Victor Civita.

Curitiba (2011). Manual do Conselho de Escola - Gestão Democrática nas Escolas Municipais de Curitiba, 2. ㄹ edição.

Curitiba (2006). Secretaria Municipal da Educação. Diretrizes Curriculares para a Educação Municipal de Curitiba. Vol. 1, Princípios e Fundamentos.

Curitiba (2009). Secretaria Municipal da Educação. Parâmetros e Indicadores de Qualidade para os Centros Municipais de educação Infantil. Curitiba: SME.

Curitiba (2011). Secretaria Municipal da Educação. Manual do Conselho - primeira versão (arquivo digital). Curitiba: SME.

Curitiba (2009). Parâmetros de Qualidade para os Centros de Educação Infantil de Curitiba.

Cury, Carlos R. Jamil (2000). Os Conselhos de Educação e a gestão dos sistemas. In: Ferreira, N. S. C.; Aguiar, M. A. (Org.). Gestão da educação: impasses, perspectivas e compromissos. São Paulo: Cortez.

Elliott, John (1997). La investigación-accióneneducación. Madrid: Ediciones Morata. 
Ferreira, Bárbara Pimpão. (2015) A qualidade a participação como princípios na gestão a serviço da defesa dos direitos das infâncias. In: Rede Marista de Solidariedade: Avaliação "da" e "na" educação infantil: significando conceitos e práticas. Curitiba: Editora Champagnat.

Garcia, Heloisa Helena Genovese de Oliveira e Macedo, Lino De. (2011) Reuniões de pais na educação infantil: modos de gestão. In: Cadernos de Pesquisa, vol41, n.142, jan./abr., p.208-227.

Kemmis, Stephen e Wilkinson, Mervyn (2011). A pesquisa-ação participativa e o estudo da prática. In Diniz-Pereira, Julio Emílio e Zeichner, K. (Org.). A pesquisa na formação e no trabalho docente. 2a․ Ed. Belo Horizonte: Autêntica.

Luiz, Maria Cecília (2010). Conselho escolar: Algumas Concepções e Propostas de Ação, São Paulo, Xamã.

Mello, Marcia Maria de (2008). Educação Infantil: Aprendizagens de Diretoras iniciantes. Dissertação de Mestrado. Programa de Pós-Graduação da Universidade Federal de São Carlos. São Carlos - SP.

Mello, Lucrécia Stringhetta e Luz, Anízia Aparecida Nunes. (2015) A importância da gestão na formação dos profissionais da educação infantil: respeito às diversidades. In: Revista eletrônica de educação, vol09, n.1, p.105-199, Recuperado em 08 de setembro de 2015 de http://dx.doi.org/10.14244/198271991076.

Molina, Rinaldo (2007). A pesquisa-ação/Investigação-ação no Brasil: mapeamento da produção (1966-2002) e os indicadores internos da pesquisa-ação colaborativa. (Tese de doutorado). Programa de Pós-Graduação da Faculdade de Educação da Universidade de São Paulo.

Monção, Maria Aparecida Guedes (2013). Gestão democrática na educação infantil: o compartilhamento da educação da criança pequena. Tese de Doutorado. Faculdade de Educação da Universidade de São Paulo. São Paulo.

Moro, Catarina. (2013): Produção Brasileira sobre Avaliação em Educação Infantil: tendências. RELAdEI (Revista Latinoamericana de Educación Infantil). Vol.2(2), p.53-68. Recuperado em 04 de dezembro de 2015 de http://www.reladei.net.

Paro, Vítor Henrique (2000). Gestão democrática da escola pública. 3ed. São Paulo: Ática.

Placco, Vera Maria Nigro de Souza e Souza, Vera Lucia Trevisan (2006) Aprendizagem do Adulto professor. São Paulo: Edições Loyola.

Tripp, David (2005). Pesquisa-ação: uma introdução metodológica. In Educação e Pesquisa, São Paulo, v. 31, n. 3, p. 443-466, set./dez..

Yuni, José e Urbano, Cláudio (2005). Mapas y herramientas para conocerlaescuela: Investigación Etnográfica/Investigación-acción. Córdoba-Argentina: Brujas.

Recebido / Received: 21/09/2016

Aprovado / Approved: 28/12/2016 